SUSín BETRÁN, R., «Apuntes para pensar el significado de la Universidad», REDUR 6, diciembre 2008, pp. I7-3I. ISSN $1695-078 \mathrm{X}$

\title{
APUNTES PARA PENSAR EL SIGNIFICADO DE LA UNIVERSIDAD ${ }^{\mathrm{I}}$
}

\author{
Raúl SUSÍN BETRÁN \\ Profesor Titular de Filosofía del DERECHO \\ UNIVERSIDAD DE LA RIOJA
}

SUMARIO: I. La crisis como punto de partida (positivo). Un primer diagnóstico. II. La educación (universitaria) en la sociedad de consumidores. De la dictadura de lo técnico y lo práctico a la insignificancia. III. La dimensión política de la universidad. Educar en el pensamiento crítico como propuesta emancipatoria. IV. A modo de breve conclusión. V. Bibliografía.

RESUMEN: La imposición de criterios mercantilizadores han hecho que la educación y las instituciones educativas, entre ellas la universidad, sean instrumentalizadas. Un tiempo de transformaciones puede ser un buen momento para recuperar la universidad como lugar privilegiado para el pensamiento crítico.

PALABRAS CLAVE: Universidad, educación, pensamiento crítico.

TITLE: Notes to Think about the Meaning of the University.

ABSTRACT: The imposition of market criteria have made that the education and the educative institutions, between them the university, were instrumentalized. A time of transformations can be a good moment to recover the university as favoured place for the critical thought.

KEYwORDS: University; education; critical thought.

\section{La crisis como punto de partida (positivo). Un primer diagnóstico}

«En la actualidad, -dice Bauman-, poca gente recuerda que la palabra 'crisis' fue acuñada para designar el momento de la toma de decisiones...Etimológicamente, el término se acerca más a ‘criterio' -el principio que aplicamos para tomar la decisión correcta- que a la familia de palabras asociada con 'desastre' o 'catástrofe', donde tendemos a situarla hoy».

\footnotetext{
${ }^{\mathrm{I}}$ Este trabajo se ha realizado en el marco del proyecto financiado por el Ministerio y con referencia SEJ2006I5335-Co2-OI.

${ }^{2}$ Bauman, Z, La sociedad individualizada, trad. Mª. Condor, Madrid, Cátedra, 200I, pág. I49.
} 
En este sentido, el momento actual puede servir de marco para una revuelta impulsada por un no exento de una cierta paradoja «nihilismo liberador» ante lo que ha sido una cultura universal y hegemónica sustentada en las falsas creencias, ilusiones y prejuicios, presentada como la cultura única y legítima, y que existía en «orden a favorecer a un grupo social determinado que establece un sistema de dominación a través de mecanismos ideológicos, simbólicos, psicológicos, más que estrictamente represivos o materiales». ${ }^{3}$

Así, y aunque es cierto que ha existido un cierto proceso de democratización de la educación al que no ha sido ajeno el Estado del bienestar corrigiendo situaciones de desigualdad, extendiendo y generalizando la educación en sus distintos niveles y facilitando el consumo de productos culturales, también es cierto que no podemos, ni mucho menos, enterrar las aportaciones cognitivas que en torno a la cultura de la distinción realiza Bourdieu; ${ }^{4}$ de quien también merece la pena recordar su recurso a la imagen del «demonio de Maxwell» como instrumento para la comprensión del funcionamiento de los mecanismos de reproducción escolar; ${ }^{5}$ o las reflexiones de Thorstein Veblen en torno a la «clase ociosa», a la apropiación de la cultura como algo natural de determinada clase y, más en concreto, al reflejo que esto tiene en la educación superior. ${ }^{6}$

De esta forma, y volviendo a la idea de crisis, se trata de pensar este tiempo como una oportunidad para, desde la universidad y el pensamiento que en ella reside, subvertir lo que ha sido hegemónico en lo cultural y en lo educativo. Para ello nos puede resultar útil acceder al diagnóstico de la crisis en el ámbito universitario que realiza Boaventura de Sousa Santos quien, hablando sobre el tránsito «De la idea de universidad a la universidad de ideas», comienza diciendo: «La universidad se enfrenta por todos lados, a una situación compleja: la sociedad le hace exigencias cada vez mayores, al mismo tiempo que se hacen cada vez más restringidas las políticas de financiamiento de sus actividades por parte del Estado». A continuación, Boaventura de Sousa Santos expone lo que considera que son «los principales parámetros de la compleja situación en que se encuentra la universidad». En este sentido, el autor identifica una serie de crisis-contradicciones que afectan a la universidad, en tanto que surgen en el marco de una superación de la unidimensionalidad y perennidad de objetivos y fines con los que ha sido pensada la universidad, y que deben ser tenidas en cuenta para comprender el significado actual de esta institución, así como para «construir el punto de vista a partir del cual la universidad debe enfrentar los desafíos que se le proponen». De esta forma, en las últimas décadas del XX se habría dado, sostiene el autor portugués, una «explosión de funciones» que plantea dudas sobre la compatibilidad entre las mismas, y que habría sido tratada más con una intención de gestión que de resolución.?

Se plantea, de este modo, una triple crisis por la existencia, a su vez, de una triple contradicción: «La contradicción entre, por un lado, la producción de alta cultura y de I84.

${ }^{3}$ Gil VilLA, F., El mundo como desilusión. La sociedad nihilista, Madrid, Ediciones Libertarias, I999, págs. I53-

${ }^{4}$ Bourdieu, P., La Distinction. Critique sociale du jugement, Paris, Minuit, I979.

5 «El sistema escolar, -dice el sociólogo francés-, actúa como el demonio de Maxwell: a costa del gasto de la energía necesaria para llevar a cabo la operación de selección, mantiene el orden preexistente, es decir, la separación entre los alumnos dotados de cantidades desiguales de capital cultural. Con mayor precisión, mediante toda una serie de operaciones de selección, separa a los poseedores de capital cultural heredado de los que carecen de él. Como las diferencias de aptitud son inseparables de diferencias sociales según el capital heredado, tiende a mantener las diferencias sociales preexistentes» (Bourdieu, P., Razones prácticas. Sobre la teoría de la acción, trad. T. Kauf, Barcelona, Anagrama, I997, pág. 35).

${ }^{6}$ Veblen, Th., Teoría de la clase ociosa, $2^{a}$ ed. $\mathrm{I}^{\mathrm{a}}$ reimp., trad. V. Herrero, México D. F., Fondo de Cultura Económica, 1992, sobre todo págs. 369-406.

7 SAnTos, B.S., De la mano de Alicia: lo social y lo político en la postmodernidad, trad. C. Bernal, Santafé de Bogotá, Ediciones Uniandes-Facultad de Derecho de la Universidad de los Andes-Siglo del Hombre Editores, I998, págs. 225-228. 
conocimientos ejemplares necesarios para la formación de las élites, de lo cual la universidad se ha venido ocupando desde la Edad Media, y por otro, la producción de modelos culturales medios y de conocimientos útiles para las tareas de transformación social y especialmente para la formación de la fuerza de trabajo calificada exigida por el desarrollo industrial». Es decir, la crisis-contradicción que se viene a manifestar en lo que denomina crisis de hegemonía y de la que, un poco más adelante dice, en relación a la universidad, que ésta «sufre una crisis de hegemonía en la medida en que su incapacidad para desempeñar cabalmente sus funciones contradictorias lleva a los grupos sociales más afectados por su déficit funcional o al Estado, en nombre de ellos, a buscar medios alternativos para alcanzar sus objetivos». En segundo lugar, «la contradicción entre la jerarquización de los saberes especializados a través de las restricciones del acceso y de la certificación de las competencias y las exigencias socio-políticas de democratización y de la igualdad de oportunidades». En otras palabras, la contradicción entre «jerarquización y democratización», la cual se vienen a manifestar como crisis de legitimidad y, para lo que afecta a la universidad, consiste en que ésta «sufre una crisis de legitimidad en la medida en que se hace socialmente visible la carencia de objetivos colectivos asumidos». Finalmente, Boaventura de Sousa Santos apunta un tercer campo de problemática, aquel que tiene que ver con «la contradicción entre la reivindicación de la autonomía en la definición de los valores y de los objetivos institucionales y la sumisión creciente a criterios de eficacia y de productividad de origen y naturaleza empresarial». O como se encarga de precisar, se trata de la contradicción que se manifiesta como crisis institucional y que a la universidad le afecta «en la medida en que su especificidad organizativa es puesta en tela de juicio y se pretende imponerle modelos organizativos vigentes en otras instituciones consideradas como más eficientes».

Crisis, pues, de la universidad, pero hay que tener en cuenta que no se trata de una crisis aislada, sino que forma parte de una crisis societal, mucho más profunda que la crisis financiera y económica de este 2008 , y de la que casi se puede decir que incluso lleva consigo una sensación de permanencia. Una crisis que debe ser leída en un contexto en el que adquieren valor político la volatilidad, la vulnerabilidad, la precariedad, la inestabilidad, la incertidumbre y la flexibilidad, hasta el punto de que se impone una economía política de la incertidumbre que provoca actitudes cortas de mira, deficitarias de proyectos a largo plazo. En otras palabras, se trata, como bien dice Bourdieu, de la realización de la utopía neoliberal de la explotación ilimitada en «un mundo sin inercia, sin principio inmanente de continuidad», en el que prima la destrucción de lo colectivo, de las identidades de grupo, el desencanto, la desmoralización y el conformismo. ${ }^{9}$ O como también ha dicho de forma expresiva Edgar Morin en su propuesta de pensar una política como antro-política, esta crisis se manifiesta como una «crisis de un hombre que se desprende de su placenta». ${ }^{\circ}$

\section{La educación (universitaria) en la sociedad de consumidores. De la dictadura de lo técnico y lo práctico a la insignificancia}

Enlazando este marco general con el ámbito del conocimiento, la educación y la universidad, tras el diagnóstico referido, Boaventura de Sousa Santos, que aporta una serie de tesis-soluciones, también enmarca la crisis de la universidad en la de una época de tránsito desde el paradigma de la modernidad al de la posmodernidad. «La idea de la universidad moderna hace parte integrante del paradigma de la modernidad. Las múltiples crisis de la

\footnotetext{
${ }^{8}$ Idem, págs 228-229.

${ }^{9}$ Bourdieu, P., Contrafuegos. Reflexiones para servir a la resistencia contra la invasión neoliberal, trad. J. Jordá, Barcelona, Anagrama, I999, págs. I36-150.

${ }^{10}$ Morin, E., Introducción a una política del hombre, trad. T. Fernández y B. Eguibar, Barcelona, Gedisa, 2002, págs. 94-95
} 
universidad son afloramientos de la crisis del paradigma de la modernidad y sólo son, por eso, solucionables en el contexto de la solución de ésta última». Continuando en la dos siguientes «tesis» insistiendo en que la crisis de los paradigmas dominantes en la ciencia moderna llevan a una época de crisis y transición desde la modernidad a la posmodernidad y arrastran con ello a la propia idea de la universidad moderna. ${ }^{\mathrm{II}}$

En una línea que conecta con lo anterior, Zygmunt Bauman reflexiona sobre los retos de la educación en la modernidad líquida y denuncia cómo vivimos en un contexto de valorización absoluta del cambio continuo, de lo efímero, y de rechazo de los compromisos, las lealtades y todo aquello que remita a algo estable y duradero, lo cual se presenta como un signo de pobreza, un «estigma de vergüenza». El «síndrome de la impaciencia» que hace que el tiempo sea considerado como una contrariedad, «un desaire a la libertad humana, una amenaza a los derechos humanos», también, por qué no, habría llegado al ámbito de la educación y del conocimiento, trasladando a éste el gusto por el consumo efímero y constante. «En el torbellino de cambios, el conocimiento se ajusta al uso instantáneo y se concibe para que se utilice una sola vez. Los conocimientos listos para el uso instantáneo e instantáneamente desechables de ese estilo que prometen los programas de software -que aparecen y desaparecen de las estanterías de las tiendas en una sucesión cada vez más acelerada-, resultan mucho más atractivos». Se trataría de un primer reto-amenaza que identifica Bauman para el conocimiento en la modernidad líquida y que acabaría por deslizar a éste hacia la consideración de una simple mercancía que adquiere valor no tanto por una cuestión de calidad, sino por el rasgo diferencial que aporta frente a los demás productos existentes, por la novedad que significa y que mañana deja de serlo y, por lo tanto, deja de suministrar valor al producto. ${ }^{\text {I2 }}$

Pero además, advierte Bauman, este primer reto-amenaza que se cierne sobre la educación y el conocimiento en la modernidad líquida se ve acentuado por «la naturaleza errática y esencialmente impredecible del cambio contemporáneo»; esto es, en un mundo en constantes transformaciones el aprendizaje y el conocimiento no quedan exentos de verse afectados. Si antes la educación, el conocimiento y el saber se pensaban para un mundo duradero en el que era posible invertir tiempo en el proceso de aprendizaje, ahora nos encontramos con que hay que salvar que el mundo, «tal y como se vive hoy, parece más un artefacto proyectado para olvidar»; un lugar donde no se pueden tener recursos persistentes ni memoria, donde el afán de aprender y de acumular conocimiento no está bien visto, y donde «el aprendizaje está condenado a ser una búsqueda interminable de objetos siempre esquivos que, para colmo, tienen la desagradable y enloquecedora costumbre de evaporarse o perder su brillo en el momento en que se alcanzan». En conclusión, y como viene a cerrar Bauman su breve ensayo sobre los retos de la educación en la modernidad líquida, los conocimientos se habrían convertido en unas mercancías más y, como tales, no serían otra cosa que «productos concebidos para ser consumidos instantáneamente, en el acto y por única vez». ${ }^{\text {I3 }}$

Como también advertíamos hace unas líneas en relación a la crisis como crisis societal, es obligado entender que las transformaciones en el aprendizaje, la educación, el conocimiento y el saber también deben ser comprendidas en el contexto más amplio que apuntamos de licuefacción de la modernidad y sobre el que tanto ha escrito Bauman. ${ }^{\text {I4 }}$ Aunque no es ahora el momento de desarrollar esta cuestión, sí que es obligado recoger cómo el significado de este tránsito de una modernidad sólida a otra líquida tiene que ver con la mercantilización de todos los aspectos de la vida y con el triunfo de la sociedad de

\footnotetext{
${ }^{\text {II }}$ SANTOS, De la mano de Alicia: lo social y lo político en la postmodernidad, cit., págs. 27I-272.

${ }^{12}$ BAUMAN, Z., Los retos de la educación en la modernidad líquida, Barcelona, Gedisa, 2007.

${ }^{13}$ Idem.

${ }^{14}$ Además de otros trabajos de Bauman que también citamos aquí, para acercarnos a esta idea de modernidad líquida, véase la publicación homónima, Bauman (2003).
} 
consumo y, con ella del síndrome consumista, aquel que se reduce, y reduce todo lo que toca, como una especie de rey Midas de la fugacidad y la transitoriedad, a velocidad, exceso y desperdicio. ${ }^{\text {I5 }}$

En la sociedad de consumidores se produce una «colonización de las relaciones humanas por parte de visiones del mundo y patrones de comportamiento a la medida de los mercados»; el mercado es el auténtico poder soberano y en su interés los propios consumidores se convierten en bienes de consumo, bienes de cambio vendibles. ${ }^{16}$ Así, plantea en otro trabajo Bauman: «El mercado ejerce actualmente de mediador en las tediosas actividades que intervienen en la formación y la finalización de las relaciones interpersonales, como son el unirse y el desunirse con otra persona, el vincularse y el desvincularse de ella, el salir con alguien y el borrar luego su nombre de la agenda del móvil, etc. Influye en las relaciones interhumanas, tanto en el trabajo como en casa, tanto en público como en los espacios privados más íntimos. Reformula y reestructura los destinos y los itinerarios de las actividades vitales de manera que ninguno de ellos evite el paso por los centros comerciales. (...) Subraya implacablemente el mensaje de que todo es o podría ser una mercancía, o, si todavía no lo es, debería ser tratado como tal; da a entender que es mejor que las cosas sean 'como mercancías' y que deberíamos sospechar de ellas (o, más aún, rechazarlas o evitarlas desde el principio) si se resisten a caer dentro del patrón de los objetos de consumo». ${ }^{17}$

De esta forma, todo se evalúa por lo que aporta al consumo, por su valor como bien de consumo, hasta tal punto de que las relaciones interpersonales, los lazos, vínculos y asociaciones entre las personas ya no son producidas sino consumidas; algo, por otra parte, en sintonía con un mundo que cambia tan rápido que pasa a ser considerado como «un contenedor lleno de objetos desechables, objetos de usar y tirar», incluyendo a los propios seres humanos, y donde, ante todo, el caminante trata de viajar ligero de equipaje, sin ataduras que entorpezcan su avance personal. ${ }^{18}$ Por eso, en esta auténtica cultura del consumo que acorta la distancia entre el usar y el tirar, los procesos de aprendizaje, y de olvidar, también se ven afectados por esta tiranía que obliga a estar en continuo movimiento. «El proceso de aprender y el proceso de olvidar tampoco tienen la menor oportunidad de escapar a la 'tiranía del momento', auxiliada y apuntalada por el continuo estado de emergencia, ni al tiempo que se disuelve en una serie de 'nuevos comienzos' dispares y aparentes, aunque engañosamente desconectados. La vida de consumo sólo puede ser una vida de aprendizaje rápido, pero también debe ser una vida en la que todo se olvida velozmente. Olvidar es tan importante como aprender, si no más importante». ${ }^{\text {I9 }}$

Las instituciones educativas y, entre ellas, las de educación superior, no son ajenas a estas tendencias mercantilizadoras y, así, parece obligado plantearse qué hacer, qué revisar y de qué forma, ante unas transformaciones sociales, políticas y culturales que han traído entre sus efectos el debilitamiento de las bases sobre las que se sustentaba la autoridad del conocimiento universitario y con él la pérdida de centralidad y autonomía de la universidad..$^{20}$ Ante esta situación Zygmunt Bauman, quien ha identificado como motivos para hablar de la pérdida de centralidad de la universidad, y además del proceso general de mercantilización, el declive paralelo de los Estados-nación en sus funciones integradoras y

\footnotetext{
${ }^{15}$ BAuman, Z, Vida de consumo, trad. M. Rosenberg y J. Arrambide, Madrid, Fondo de Cultura Económica de España, 2007, págs. II9-I2I.

${ }^{16}$ Idem.

${ }^{17}$ Bauman, Z., La vida líquida, trad. A. Santos Mosquera, Barcelona, Paidós, 2006, págs. II9-I20.

${ }^{18}$ BAUMAN, La sociedad individualizada, cit., págs. I77-I84.

${ }^{19}$ BAUMAN, Los retos de la educación en la modernidad líquida, cit., pág. I33.

${ }^{20}$ Ejemplo de esta pérdida de autonomía es la publicación, finales de noviembre de 2008 , de un análisis realizado por el Lisbon Council en el que un elemento básico para medir la calidad de la universidad es el criterio de la efectividad, esto es, la capacidad de producir titulados según las necesidades del mercado de trabajo.
} 
de promoción de modelos ideológicos y culturales, la extensión de la pluralidad cultural o, entre otros, la pérdida del monopolio en la decisión de los cánones de capacidad y competencia profesional, nos propone tres estrategias posibles a seguir. «Una estrategia evidente es aceptar las nuevas reglas y jugar con arreglo a ellas. En la práctica, esto significa someterse a los estrictos criterios del mercado y medir la 'utilidad social' de los productos universitarios por la presencia de una 'demanda de compensación', tratando la pericia que pueden ofrecer las universidades como una mercancía más que todavía tiene que luchar por hacerse un sitio en los abarrotados estantes del supermercado, como una mercancía más cuya calidad todavía ha de probarse según su éxito de comercialización».

Como también recoge Salvador Giner en esta misma dirección, esta estrategia supone tratar a la universidad como una empresa y al conocimiento como una mera mercancía, convirtiendo a la vez a los profesores universitarios en una suerte de mercaderes o simples vendedores a los que no llega a importar al final tanto la calidad del producto como la venta del mismo. Para este fin la universidad se comprende como un mero instrumento mercantil que se mueve según dictan los caprichos del mercado. Dejando a un lado sus compromisos y responsabilidades en el plano científico, de investigación, de cultura, de formación general, de humanización y ética, la universidad se desliza, de acuerdo con esta estrategia, hacia una pendiente utilitarista en la que la «demanda social» viene determinada por el corto plazo, lo perentorio, las modas, los intereses clasistas y, peor aún, los intereses personales. Frente a la interpretación utilitarista de «demanda social» a la que se enfrenta la universidad hoy, Giner, consciente de la «incertidumbre endémica del mundo de hoy», defiende la exigencia de pensar a largo plazo. De esta forma, concluye su exposición: «He aquí pues una situación paradójica: para responder adecuadamente a las exigencias a corto plazo de la ciudadanía a la que se debe la Universidad, ésta tiene que pensar sus estrategias y su misión en términos de largo plazo por lo que se refiere a la formación de los profesionales que en ella se educan. Y tiene que pensar, contra todo utilitarismo vulgar, en términos de servicio y fomento de una cultura, cuyos frutos han de ser necesariamente intangibles. La presencia de la razón y de la buena vida en una sociedad no dependen ciertamente sólo de la Universidad. Pero son hoy inconcebibles sin ella. Son inconcebibles, esto es, sin una Universidad que no abdique de la tarea de ser, ante todo, y más allá de toda demanda social, la casa del saber, la morada de la libertad». ${ }^{21}$

Junto a esta opción, Bauman presenta como «estrategia contraria» aquella que en lugar de ceder a las reglas de juego del mercado, como la anterior, consiste en «quemar los puentes: retirarse de la situación sin salidas en el mercado a una fortaleza construida con un lenguaje esotérico y una teoría oscura e impermeable». Es decir, si de la anterior estrategia podía interpretarse que suponía unos movimientos hacia fuera, ésta refleja un intento de replegarse tras los altos y espinosos muros de los «cuarteles» universitarios; o, si se prefiere, tras las elitistas almenas de sus «torres de marfil», lo cual no es tanto un reflejo de su autonomía como del camino del aislamiento y de la irrelevancia social por el que opta. En ambos casos, no obstante, Bauman encuentra un punto común, pues, como él mismo afirma: «Las dos anuncian el final de la 'autonomía' de la actividad universitaria (...) y de su 'posición central' en la labor intelectual. Ambas estrategias, cada una a su manera, significan la rendición».

\footnotetext{
${ }^{21}$ Cfr. Giner, S., «La Universidad y la falacia utilitarista», documento del encuentro «Los objetivos de la Universidad ante el nuevo siglo», Universidad de Salamanca, noviembre I997 (disponible en www.crue.org). Vid. también PeCes-BARbA, G., «La demanda social a finales del siglo XX», documento del encuentro «Los objetivos de la Universidad ante el nuevo siglo», Universidad de Salamanca, noviembre I997 (disponible en www.crue.org), donde se exponen algunas claves para que la universidad, aun atenta a las demandas sociales de la población en general, del estudiante modelo, o de las empresas e instituciones, atienda a las mismas de acuerdo a su posición central en el marco de una sociedad democrática. Tanto este trabajo de Peces-Barba como el anterior de Giner son dos aportaciones que se presentaron en la Conferencia «Los objetivos de la Universidad ante el nuevo siglo» hace ahora ya una década, pero que, según creo, conservan hoy todavía validez para pensar nuestras universidades.
} 
Frente a esta «rendición», Bauman nos propone una tercera opción que supone reconocer la novedad de la situación actual a través de una revisión de sus fines estratégicos y de las reglas de sus objetivos, desde donde se pretende recuperar la centralidad de la universidad y servir, en mi opinión, como una estrategia de resistencia orientada hacia el rearme democrático de las sociedades de hoy. De esta forma, sostiene Bauman la defensa de una institución que afronte el cambio y sus exigencias a través de la «pluralidad y multiplicidad de significados». Así, la clave para afrontar el reto dibujado por los dominantes registros de incertidumbre actual pasa, según el citado sociólogo, por romper con el anquilosamiento del saber impuesto en unas ocasiones desde fuera, por ejemplo, a través de la labor de los legisladores, y en otras desde dentro, por la dinámica de las mismas universidades. «Es esta multiplicidad de significados la que ofrece a las universidades la posibilidad de salir triunfante del reto actual. Para las universidades es una suerte que haya tantas, que no haya dos exactamente iguales y que dentro de cada una haya una pasmosa variedad de departamentos, escuelas, estilos de pensamiento, conversación e incluso preocupaciones estilísticas. Es una suerte para ellas que (...) no sean comparables ni se las pueda medir por el mismo rasero (...). Sólo estas universidades tienen algo de valor que ofrecer a un mundo de significados múltiples repleto de necesidades descoordinadas, posibilidades autoprocreadoras y elecciones automultiplicadoras». Concluyendo su reflexión defendiendo, como condición sine qua non de un sistema universitario a la altura del reto postmoderno, «el reconocimiento de muchos y variados caminos hacia el saber superior y de muchos y variados cánones de éste». ${ }^{22}$

Esta tercera opción ha de ser leída como una opción estratégica desde la que la universidad levante posiciones de resistencia ante la idea de insignificancia que se impone y a la que no resulta ajena la educación superior. En un diálogo con Octavio Paz en torno a que vivimos tiempos de «nihilismo complaciente», Cornelius Castoriadis caracteriza el mundo contemporáneo con esta idea de insignificancia, y dice de ella: «La insignificancia no es simplemente un estado que se ha instalado en el mundo contemporáneo, sino (...) una especie de desierto que se extiende. (...) Se trata de una especie de nihilismo, pero irrisorio»; el cual, por su parte, no deja de tener reflejo en el ámbito educativo, pues existe una cierta desaparición o, cuando menos, desconfianza hacia la cultura heredada. No hay un objeto claro de qué transmitir en las diferentes instancias educativas, entre ellas las superiores, que se dejan arrastrar por una tendencia tecnificadora que lleva a su instrumentalización y a la de la educación misma. ${ }^{23}$

Así, y como venimos diciendo, conviene precisar sobre esta insignificancia que su denominación no puede llevar a engaño y que se trata de algo para nada inocuo en relación a la educación. Es cierto que el tema de la función económica de la educación no es algo nuevo. ${ }^{24}$ Pero también es cierto que hoy, en el contexto de unas reformas de los estudios universitarios marcadas por el denominado Espacio Europeo de Educación Superior se pretende imponer un modelo educativo en el que la educación gire al ritmo que marcan las exigencias y las necesidades del mercado y el imperativo del crecimiento económico. En este sentido, Bauman analiza la Comunicación de la Comisión de las Comunidades Europeas publicada con fecha de 2I de noviembre de 200I y con el título «Hacer realidad

\footnotetext{
${ }^{22}$ BAUMAN, La sociedad individualizada, cit., págs. I43-159.

${ }^{23}$ Las cita de Castoriadis arriba recogida forma parte de una recopilación de conversaciones y diálogos de éste con distintos personajes de diferentes ámbitos, como el también citado Octavio Paz. Cfr. CASTORIADIS, C., La insignificancia y la imaginación. Diálogos con Daniel Mermet, Octavio Paz, Alain Finkielkraut, Jean-Luc Donnet, Francisco Varela y Alain Connes, trad. J. R. Capella, Madrid, Trotta, 2002, sobre todo, págs. 13-63.

${ }^{24}$ En relación a esto, al papel que desarrolla la educación en la producción, y a cómo desde una ideología economicista se ha cuestionado y puesto fin a la ideología humanista que le era propia sustituyéndola por otra de carácter económico en la que mandan los criterios mercantiles, puede verse, SEGRÉ, M., TANGUY, L. y LORTIE, M. F., «Una nueva ideología de la educación», en Labarca (comp.), Economía política de la educación, México, Editorial Nueva Imagen, I980, págs. 33I-37I. Vid. también el análisis que sobre la relación entre el modelo de producción capitalista y la educación encontramos en GougH, I., Economía política del Estado del bienestar, trad. G. Rodríguez Cabrero, Madrid, H. Blume Ediciones, I982, sobre todo págs. 97-99.
} 
un espacio europeo del aprendizaje permanente». «Desde su primera página, -dice Bauman-, el documento habla de la necesidad de extender la educación/aprendizaje permanente para adquirir 'condiciones competitivas ventajosas' que 'dependen cada vez más de la inversión en capital humano', y de que el conocimiento y las aptitudes se conviertan en 'un poderoso motor del crecimiento humano'. Según la Comisión, la importancia y la necesidad del aprendizaje a lo largo de toda la vida radican en su papel como 'fomentador de una fuerza de trabajo cualificada, formada y adaptable'». Se enfatiza el aprendizaje frente a la educación y se apuesta por un aprendizaje de las aptitudes que requiere un mercado de trabajo muy volátil, en continuo cambio, lo que no hace sino provocar continuas situaciones de inadaptación y de ausencia de dominio. Si el aprendizaje/educación debe ir dirigido a formar trabajadores útiles para el mercado y éste se mueve hoy en un contexto de liquidez ya comentado, el resultado dista mucho de ser una educación que sirva al empoderamiento de los ciudadanos, entendiendo por éste la capacidad de tener control sobre nuestras opciones vitales. «Para que el 'empoderamiento' sea de verdad, es necesario adquirir no solo las habilidades exigidas para jugar a un juego diseñado por otros, sino también los poderes o las competencias que permiten influir en los objetivos, las apuestas y las reglas del juego: es decir, no sólo las habilidades personales, sino también las competencias sociales». Y como viene a concluir un poco más adelante este autor: «En definitiva, una de las cuestiones más decisivas que está en juego con la educación permanente orientada al 'empoderamiento' es la de la reconstrucción de un espacio público (cada vez más desierto en la actualidad) en el que los hombres y las mujeres puedan participar en una traslación continua entre lo individual y lo colectivo, entre los intereses, los derechos y los deberes de índole privada y los de índole comunal». ${ }^{25}$

\section{La dimensión política de la universidad. Educar en el pensamiento crítico como propuesta emancipatoria}

Esto es, de lo que se trata en estos simples apuntes es de aportar una visión del significado de la universidad en el que se valorice el conocimiento crítico, y de alertar ante el peligro de que una excesiva confianza en la exclusividad del aprendizaje y la acumulación de aptitudes técnico-prácticas puede hacer que las universidades se conviertan en unos centros que amenazan con definirse como meros instrumentos mercantiles. Pero, sobre todo, lo que nos interesa es vincular lo que es la educación, en este caso la educación superior, con la recuperación y el empoderamiento del ciudadano de cara a que éste sea capaz de asumir un control sobre su vida. En este sentido, no está de más aquí insistir en la afirmación del carácter social de la educación como un sistema público de transmisión no sólo de información y conocimientos, sino también de valores y criterios que nos humanizan. Durkheim que resalta la función de la educación en la constitución del ser social, afirma: «La educación es la acción ejercida por la generaciones adultas sobre las que no están aún maduras para la vida social. Tiene por objeto suscitar y desarrollar en el niño determinado número de estados físicos, intelectuales y morales que reclaman de él, por un lado la sociedad política en su conjunto, y por otro lado, el medio especial al que está particularmente destinado». ${ }^{26}$

Victoria Camps, que resalta la urgencia de repensar la educación en un tiempo marcado por la incerteza, la inseguridad y la desorientación, anima a comprender la educación en clave democrática, vinculando democracia y educación. Siguiendo a Adorno dice: «Luchar contra la barbarie que emerge incluso en los países aparentemente más civilizados debería ser la finalidad máxima de la educación. (...) Deberíamos coincidir en

\footnotetext{
${ }^{25}$ BAUMAn, La vida líquida, cit., págs. I55-169. Para consultar el documento arriba citado se ha acudido, con fecha de 2I de noviembre de 2008, a: http://ec.europa.eu/education/policies/111/11l_es.html

${ }^{26}$ Durkheim, E., Educación y Sociología, Buenos Aires, Shapire, I974, págs. I6 y ss.
} 
que el objetivo de la educación no es sólo la transmisión de conocimientos, sino más bien la 'consecución de una conciencia cabal'. Pues es indiscutible que la democracia necesita personas emancipadas, personas capaces de adaptase al mundo sin ceder totalmente ante él, personas que sepan prescindir de los modelos y formarse una voluntad autónoma utilizando el pensamiento. En eso consiste la emancipación». Para continuar, en esta misma dirección, reivindicando la potencialidad emancipadora de la educación en democracia, y concretando algo más el significado de esta educación emancipatoria en la que resulta básica su aportación a la recomposición de la ciudadanía: «Educar para la emancipación es tratar de vencer esa incapacidad de pensar por uno mismo, de atreverse y arriesgarse. (...) Educar es intentar que lo mejor de cada uno aflore a la superficie. (...) Educar significa, desde tal perspectiva, incitar a la reflexión, al descontento, a la crítica. A través de la información y de los mensajes que nos llegan, a través de la transmisión de conocimiento que se realiza desde la escuela hasta la universidad o la formación continua, ha de ser posible generar esa incomodidad frente a un mundo que deja mucho que desear y que no camina en la dirección más correcta. Educar es producir inquietud ética, no dar soluciones sobre el bien y el mal. (...) Educar es tratar de recomponer la ciudadanía en un mundo descompuesto porque faltan los referentes que antaño fueron indiscutibles». ${ }^{27}$

Conectado con lo anterior, al comienzo de un capítulo titulado «el aprendizaje ciudadano» dice Edgar Morin: «La educación debe contribuir a la autoafirmación de la persona (aprender y asumir la condición humana, aprender a vivir) y aprender a convertirse en un ciudadano». ${ }^{28} \mathrm{Y}$ en todo este proceso formativo la universidad tiene la responsabilidad, a la vez que intenta recuperar la centralidad que la ha caracterizado como institución, de contribuir a replantear la educación como un proceso en el que, como venimos diciendo, no sólo se adquieren conocimientos técnicos, sino, sobre todo, habilidades y capacidades que nos ayuden a existir. ${ }^{29}$ De esta forma, se trata, como bien recoge este autor, de aprovechar esta «era del caos» para solventarla de una forma positiva, estableciendo los cimientos necesarios que nos permitan resolver unos problemas que «no son sólo de hambre y demografía, sino de relaciones entre etnias y razas, entre grupos e individuos, entre persona y persona». Para este establecimiento de los cimientos, Edgar Morin propone una serie de pasos con los que se persigue, en esencia, una nueva forma de pensar la vida, o como especifica, la constitución de núcleos de partida de una nueva cultura como núcleos, a la vez, de resistencia, y desde los que acceder a una concepción de la vida en la que domine una perspectiva de sentido antropológico..$^{\circ}$

Así, en mi opinión, la educación en la universidad debe reivindicarse asumiendo la responsabilidad de lo que hoy se plantea como «la reforma del pensamiento», a la que se encuentra íntimamente ligada en su desarrollo histórico la institución universitaria. «La

${ }^{27}$ CAMPS, V., «Educación y cultura democrática», en S. Giner (coord.), La cultura de la democracia: el futuro, Barcelona, Ariel, 2002, págs. IO2-II2.

${ }^{28}$ Morin, E., La mente bien ordenada. Repensar la reforma. Reformar el pensamiento, trad. Ma. J. Buxó y D. Montesinos, Barcelona, Seix Barral, 2000, pág. 83.

${ }^{29}$ «El joven que acude a la universidad buscando el conocimiento acaba también encontrando en ella un marco de referencia para su vida futura. Va a aprender a definir objetivos, alcanzar metas, resolver problemas. Es evidente que encontrará cada una de esas habilidades en el área en la que vocacionalmente encaje. El que eligió derecho y el que fue a estudiar ingeniería descubren mecanismos distintos. Quien estudia ingeniería tiene más facilidad con los métodos cuantitativos. Quien estudia derecho tiene más destreza con métodos de otro orden. Pero uno y otro van en busca de un rasgo común, que es la habilidad para usar el saber, considerando el análisis y la solución de problemas del mundo real» (MARCOVITCH, J., La universidad (im)posible, trad. Y. Machado, Madrid, Cambridge University Press, 2002, pág. I8).

${ }^{30}$ Morin, Introducción a una política del hombre, cit., págs. I29-I30. Por otra parte y en relación a este «lado positivo» que se puede extraer de esta «era del caos», Morin señala en otro texto la importancia, precisamente, del conocimiento de la «incertidumbre»: «La mayor aportación del conocimiento del siglo XX ha sido el conocimiento de los límites del conocimiento. La mayor certidumbre que nos ha dado es la de la imposibilidad de eliminar ciertas incertidumbres, no sólo en la acción sino también en el conocimiento» (MoriN, La mente bien ordenada. Repensar la reforma. Reformar el pensamiento, cit., págs. 72-73). 
reforma de la universidad no puede contentarse con una democratización de la enseñanza universitaria, y de la generalización del estado de estudiante. Se trata de una reforma que concierne a nuestra aptitud para organizar el conocimiento, es decir para pensar». ${ }^{3 \mathrm{I}}$ Por ello, en esta universidad si bien no se pueden dejar a un lado los conocimientos técnicos y cada vez más especializados que exigen las complejas sociedades contemporáneas, se debe pensar en proporcionar un tipo de conocimiento que permita superar lo inmediato, que no se quede estancado en saberes y áreas de conocimiento cerrados y que aporte una visión transdisciplinar que, a su vez, sirva en la construcción de una ciudadanía que sepa hacer frente a la incertidumbre. Al concluir la defensa de una serie siete principios-guías con los que vertebrar un «pensamiento que conecte», Edgar Morin afirma: «Esto nos indica que un modo de pensar capaz de unir y solidarizar conocimientos separados es capaz de prolongarse en una ética de la interrelación y de la solidaridad entre humanos. Un pensamiento capaz de no quedarse encerrado en lo local y lo particular sino de concebir los conjuntos sería apto para favorecer el sentido de la responsabilidad y de la ciudadanía. La reforma del pensamiento tendría pues consecuencias existenciales, éticas y ciudadanas». ${ }^{32}$

Por otra parte, si realmente se asumiera la necesidad de que la universidad tuviera en cuenta este carácter social en la comprensión de la enseñanza, la educación y el conocimiento, la universidad resaltaría su dimensión política de primer orden en la sociedad de hoy. En este sentido, en un texto donde se recogen trabajos en torno al pensamiento de Ignacio Ellacuría podemos leer: «Democratizar la Universidad es evidentemente mucho más que crear un generoso sistema de becas o un ambicioso plan de cuotas diferenciadas que permitan el ingreso a sus aulas de alumnos económicamente débiles (aunque esto sea necesario); democratizar la Universidad quiere decir ponerla al servicio integral del pueblo, hacerla vibrar con sus necesidades y problemas, identificarla con sus luchas, fracasos y sufrimientos, ponerla a soñar y a trabajar en la resolución de su marginación histórica y en la transformación de sus esquemas sociales. Todo esto implica el abandono de todo tipo de relación vertical y dominadora por un tipo de relación dialogal y por un trabajo de cooperación realmente activa». ${ }^{33}$ De la misma forma que la universidad puede servir para la reproducción de un estado de «conformismo generalizado», lo cual no deja de ser una función política, puede mutar su papel «domesticador» por otro en el que se posibilite la reflexión democrática y crítica, en la cual el estudiante deja de ser un mero sujeto pasivo y se convierte en protagonista del «estamento dialécticamente dinamizador». «Para ello, (...) es preciso que el clima universitario sea un clima radical pero exigentemente crítico, y que el estudiante penetre en este ámbito para traducir en un cuestionamiento científico a la realidad toda la inquietud y el malestar del que de hecho es portador, como producto de nuestra sociedad actual. (...) Donde existe un ambiente democrático y abiertamente crítico, el estudiantado puede jugar un papel fundamental, (...) puede constituirse en el despertador de la conciencia al servicio de la causa histórica de un pueblo». ${ }^{34}$

En una línea similar, el citado Ellacuría defiende la ineludibilidad de este sentido político de la universidad, la evidencia de su virtualidad política, diciendo: «El sentido último de una Universidad y lo que es en su realidad total debe mensurarse desde el criterio de su incidencia en la realidad histórica, en la que se da y a la que sirve. Debe mensurarse, por tanto, desde un criterio político. Esta afirmación puede parecer, a primera vista, que lleva a una

\footnotetext{
${ }^{31}$ Idem, pág. III.

${ }^{32}$ Vid. idem, págs. I08-128, donde, además de la cita arriba recogida, el autor nos aporta una reflexión sobre la vinculación de las reformas en el pensamiento y en la enseñanza en la universidad, llegando a proponer, entre otras medidas concretas, y además de los ya citados siete principios-guías, la institución en todas las universidades y facultades de lo que expone como «un diezmo epistemológico o transdisciplinario, que deduciría un Io\% del tiempo del curso para una enseñanza común que trataría de los diferentes saberes y las posibilidades de hacer que se comunicaran».

${ }^{33}$ MARTín BARÓ, I., «El estudiantado y la estructura universitaria», en VV. AA., Universidad y cambio social (Los jesuitas en El Salvador), México D. F., Magna Terra Editores, I990, pág. I23.

${ }^{34}$ Idem, págs. I23-I24.
} 
politización desfiguradora de la auténtica labor universitaria en lo que tiene de esfuerzo teórico por saber y posibilitar un hacer desde ese saber. Sin embargo, no tiene por que ser así. Y para que no lo sea es necesario preguntarse muy explícitamente por la dimensión política de la Universidad, porque esta dimensión es un hecho innegable y un hecho de grandísima importancia para la orientación misma de la Universidad. El carácter distinto de la Universidad no estará, entonces, en no cumplir con su misión política, sino en cumplirla de otra manera. Esa es la cuestión. Si no la afronta, además de dar paso a constantes contradicciones internas que tensionan y acaban imposibilitando el trabajo universitario, dejan a la Universidad sin norte y, lo que es peor, a merced de las presiones incontroladas por ella». ${ }^{35}$

El mismo Ellacuría nos precisa que la potencialidad política de la universidad no debe confundirse con lo que considera «dos formas inadecuadas y falsificadas de cumplir con esta misión política». De una parte, aquella que contribuye a mantener y fortalecer el sistema; de otra, la que desde una posición que tiene como fin último la toma del poder se enfrenta al sistema asumiendo una determinada orientación política que le hace perder sentido crítico. Frente a estas dos formas que, además, han sido las dominantes en la misión política de la universidad, se nos propone que «la Universidad, por su propio carácter crítico, por su fundamental necesidad de racionalidad y de eticidad, no puede reducirse a favorecer indiscriminadamente ningún sistema político ni ningún sistema social dado; pero tampoco puede, en el fondo por el mismo talante de racionalidad y de eticidad, abandonar su propio modo universitario de enfrentarse con la realidad social». A partir de allí, el propósito del autor es realizar «la pretensión de una Universidad distinta» en el cumplimiento de su misión política. Para ello, y a través de cuatro preguntas, se propone definir lo que serían las características propiamente universitarias de la misión política de la universidad. ${ }^{36}$ De esta forma, Ellacuría alcanza a concluir: «Considerados a una las grandes mayorías oprimidas como horizonte, el cultivo de la realidad nacional como campo, la palabra eficaz como modo propio de acción, la beligerancia como talante y la transformación estructural como objetivo, no es difícil reconocer una clara misión política y un estricto carácter universitario a esta definición de la actividad de la Universidad». O como a continuación podemos leer, con la advertencia presente de que este texto se redacta en el complejo contexto de El Salvador de mitad de los setenta: «La realidad históricopolítica es el lugar adecuado para interpretar correctamente el trabajo universitario; si no se le enfoca desde esa su absoluta concreción, la Universidad estaría desempeñando irreflexivamente su papel y utilizando irresponsablemente su gran potencial. Por otra parte, si no busca decididamente ser fiel a su propia esencia universitaria se podría hablar de la misma irreflexión y de la misma irresponsabilidad (...). No hay contradicción alguna entre Universidad y política; al contrario, ambas se necesitan mutuamente y se potencian». ${ }^{37}$

Tal vez estas reflexiones que acabamos de recoger aporten algo de luz sobre el tema del sentido político de la universidad, así como, también, sobre su significado como referente ético. Por lo menos, creo, nos pueden servir para ahuyentar falsos equívocos, más o menos intencionados, entre política y partidismo. Y, sobre todo, creo que nos permiten apostar por una superación de la oposición universidad-política, reivindicando la realización de la misión política desde posiciones universitarias; pero, a la vez, siendo plenamente conscientes de los no pocos riesgos que existen en la realización de esta misión desde una

${ }^{35}$ Ellacuría, I., «Diez años después ¿Es posible una Universidad distinta?», en VV. AA. Universidad y cambio social (Los jesuitas en El Salvador), México D. F., Magna Terra Editores, I990, pág. I34.

${ }^{36}$ Vertebra Ellacuría su propuesta contestando a cuestiones sobre el horizonte de la actividad universitaria, el campo propio de esa actividad, su modo de actuación, su talante fundamental y su objetivo inmediato. Vid. idem, págs. 136 y ss.

${ }^{37}$ Idem, págs. I35-I46. Hablando de ética y universidad y del papel de ésta, Marcovitch nos aclara algo sobre la relación política-universidad: «Es su papel alertar, avisar, informar. Pero no podemos imaginar que la universidad asuma responsabilidades que son de los gobiernos y partidos políticos. La universidad puede y debe divulgar valores y preocupaciones, pero compete a los partidos políticos y sectores dirigentes la presentación e implantación de propuestas» (MARCOVITCH, La universidad (im)posible, cit., pág. 39). 
perspectiva crítica. Haciendo un paréntesis, estos riesgos, que en cualquier caso no dejan de tener conexión con la política, también los encontramos en el propio conocimiento científico, desde una perspectiva más amplia, y, de forma más concreta, entre los intelectuales y la política, como bien se han encargado de señalar diferentes autores. En referencia únicamente a lo primero, pues lo otro, la relación intelectuales-política, se nos escapa de la intención de este trabajo, cabe recoger las reflexiones que en torno al conocimiento sociológico realiza Bourdieu en la lección inaugural que impartió con ocasión de su ingreso en el Collège de France en 1982. En este sentido, el sociólogo francés defiende una sociología que proporcione un conocimiento superador de falsas verdades con las que se acaba construyendo objetivaciones parciales aunque pretendidamente neutras en tanto que científicas. Así, entre las líneas desmitificadoras de la lección podemos leer: «Cualesquiera que sean sus pretensiones científicas, la objetivación está abocada a seguir siendo parcial, por lo tanto falsa, mientras ignore o se niegue a ver el punto de vista a partir del cual se enuncia, es decir el juego en su conjunto. Establecer el juego como tal, es decir como un espacio de posiciones objetivas que está en el origen, entre otras cosas, de la visión que los ocupantes de cada posición puedan tener de las demás posiciones y de sus ocupantes, significa dotarse del medio para objetivar científicamente el conjunto de las objetivaciones más o menos brutalmente reductoras en las que incurren los agentes implicados en la lucha, y tomarlas por lo que son, estrategias simbólicas que tratan de imponer la verdad parcial de un grupo como la verdad de las relaciones objetivas entre los grupos»..$^{8}$

En cualquier caso, para ir acabando, y volviendo a centrarnos en la misión política de la universidad, en las líneas que han conformado este trabajo se ha optado por una posición en la que late una preocupación por conseguir que ésta no se convierta en un mero referente para el acceso a conocimientos científicos y técnicos que, por otro lado, nadie dice que no tengan que estar. Valorizar la universidad, desinstrumentalizándola de los intereses del mercado, nos debería llevar a abandonar, o a matizar, que pido bien poco, la visión que de la misma impulsa una especie de pensamiento racionalista-cientifista para el que lo principal, lo único, reside en la supremacía de los conocimientos técnicos. Giner de los Ríos, que debía saber algo de esto, defendía que la universidad actuase como una suerte de conciencia ética de la vida. El impulsor de la Institución Libre de Enseñanza recogía, en la distancia de hace Ioo años, la existencia de un interés en que las instituciones universitarias proporcionasen una «educación total» que fuera más allá de sus muros y así, sobre la universidad que asomaba en el inicio del XX, decía que «tiende a ser, no sólo una corporación de estudiantes y sabios, sino una potencia ética de la vida». ${ }^{39}$

\section{A modo de breve conclusión}

Jonathan Swift se refiere en los viajes de Gulliver a la Academia de Proyectistas de Lagado, en el territorio de Balnirbari, y dice de ella que era un centro creado por un grupo de personas de ese territorio que habiendo subido a la Isla Voladora, Laputa, volvieron de ella con una mentalidad proyectista ajena a toda racionalidad. En ese centro residían personajes que se dedicaban a inventar los más absurdos sistemas y métodos destinados a las artes, las ciencias, los idiomas y las industrias y tecnologías. Por ejemplo, el primero al que se refiere Gulliver era el de un hombre que estudiaba la posibilidad de extraer rayos de sol de los pepinos. Tras describir sus abandonados aspecto físico y vestimenta, dice: «Llevaba ocho años en un proyecto para extraer rayos de sol de los pepinos, rayos que, una vez envasados en frascos herméticamente cerrados, podrían soltarse para que caldearan el ambiente en veranos recios y destemplados. Me dijo que no dudaba que en el plazo de otros

\footnotetext{
${ }^{38}$ Bourdieu, P., Lección sobre la lección, trad. T. Kauf, Barcelona, Anagrama, 2002, págs. 24-25.

${ }^{39}$ Giner de los Ríos, F., La Universidad española, Madrid, Civitas, 200I, págs. II4-I26.
} 
ocho años podría abastecer de luz solar los jardines del Gobernador a un precio razonable, pero se quejaba de andar escaso de caudales y me suplicó que le diera algo a manera de estímulo al ingenio, especialmente porque aquel año los pepinos estaban muy caros». Continúa Swift en boca de Gulliver hablando de proyectos que abarcan distintas disciplinas, incluso del orden especulativo y político, y a través de los cuales se lee una satírica crítica de algunas investigaciones desarrolladas en Academias y Sociedades científicas de su época. ${ }^{4}$ No creo que las instituciones universitarias deban ser un reducto extraño y aislado de un conocimiento inútil del tipo del recogido en la Academia de Proyectistas de Lagado; sin embargo, tampoco estoy muy convencido de que convenga reducir a la universidad a un manejo triste de conocimientos técnico-prácticos, de academia con minúsculas. Ahora que se está en un momento de transformaciones, y en el que un tiempo importante es el de los planes de estudio, podría ser conveniente que, serenamente hablando, no pensásemos de forma excluyente la obligación de la universidad en la transmisión de información y conocimientos técnicos, o en la formación en destrezas y habilidades prácticas, o en tener en cuenta las necesidades de la sociedad y del mercado, Un actitud excluyente nos llevaría a renunciar a una de las dimensiones que creo más interesantes de la universidad, la de ser un espacio privilegiado para el pensamiento crítico.

Baudrillard, siempre tan hábil en el manejo de las palabras, dice sobre este pensamiento crítico: «El pensamiento tiene que desempeñar un papel catastrófico, ser él mismo un elemento de catástrofe y de provocación en un mundo que se empeña en depurarlo todo, exterminar la muerte y la negatividad. Pero al mismo tiempo tiene que seguir siendo humanista, preocupándose por lo humano, y recuperar para ello la reversibilidad del bien y del mal, de lo humano y lo inhumano». ${ }^{4 \mathrm{~T}}$ Sólo en la medida en que seamos capaces de ser amables y acogedores con este pensamiento crítico podremos decir que disponemos de una «universidad sin condición», como espacio en el que la libertad incondicional de palabra y de cuestionamiento se encuentra garantizada de forma absoluta.

Si la universidad históricamente se ha venido caracterizando por su contribución en el impulso de la secularización del saber, del espíritu científico y del progreso regulado por la razón desde una perspectiva humanista, hoy la universidad moderna debe considerarse heredera directa de los valores de la Ilustración y, sobre todo, de su aportación de «luz». En este sentido, y para todo, se requiere, como recoge Derrida, una «universidad sin condición» y comprometida con la verdad: «La universidad moderna debería ser sin condición. Entendamos por 'universidad moderna' aquella cuyo modelo europeo, tras una rica y compleja historia medieval, se ha tornado predominante, es decir 'clásico', desde hace dos siglos, en unos Estados de tipo democrático. Dicha universidad exige y se le debería reconocer en principio, además de lo que se denomina la libertad académica, una libertad incondicional de cuestionamiento y de proposición, e incluso, más aún si cabe, el derecho de decir públicamente todo lo que exigen una investigación, un saber y un pensamiento de la verdad. (...) La universidad hace profesión de la verdad. Declara, promete un compromiso sin límite para con la verdad. Sin duda, el estatus y el devenir de la verdad, al igual que el valor

\footnotetext{
${ }^{40}$ SwifT, J., Los viajes de Gulliver, trad. P. Hernúñez, Madrid, Anaya, 200I, págs. 215-235.

${ }^{41}$ BAUdrillard, J., Contraseñas, trad. J. Jordá, Barcelona, Anagrama, 2002, págs. 92-93. Sobre las palabras y su relación con el pensamiento, dice este autor al iniciar el texto y explicar la utilización del término «contraseñas» como título: «Las palabras poseen para mí una importancia extrema. Que poseen una vida propia, $y$, por consiguiente, son mortales, es evidente para cualquiera que no reivindique un pensamiento definitivo, con pretensiones edificantes. Lo que es mi caso. La temporalidad de las palabras expresa un juego casi poético de muerte y renacimiento: las metamorfosis sucesivas hacen que una idea crezca y se convierta en algo más que ella misma, en una 'forma de pensamiento', pues el lenguaje piensa, nos piensa y piensa por nosotros tanto, por lo menos, como nosotros pensamos a través de él. (...) Creemos que avanzamos a base de ideas -ésta es sin duda la fantasía de cualquier teórico, de cualquier filósofo-, pero son también las propias palabras las que generan o regeneran las ideas» (idem, págs. 9-10).
} 
de verdad, dan lugar a discusiones infinitas (...). Pero eso se discute justamente, de forma privilegiada, en la Universidad».42

Ocurre, sin embargo que el ser, como tantas otras veces, está muy lejos de adecuarse al deber ser. Por ello el propio Derrida reconoce que esta universidad sin condición no existe hoy de hecho. Pero de la misma forma también afirma que «en principio y de acuerdo con su vocación declarada, en virtud de su esencia profesada, ésta debería seguir siendo un último lugar de resistencia crítica -y más que crítica- frente a todos los poderes de apropiación dogmáticos e injustos». ${ }^{43}$

\section{Bibliografía}

BAUdRILlard, J., Contraseñas, trad. J. Jordá, Barcelona, Anagrama, 2002.

Bauman, Z, La sociedad individualizada, trad. Mª . Condor, Madrid, Cátedra, 200I.

- La modernidad líquida, trad. M. Rosenberg y J. Arrambide, México, Fondo de Cultura Económica, 2003.

— La vida líquida, trad. A. Santos Mosquera, Barcelona, Paidós, 2006.

- Los retos de la educación en la modernidad líquida, Barcelona, Gedisa, 2007.

- Vida de consumo, trad. M. Rosenberg y J. Arrambide, Madrid, Fondo de Cultura Económica de España, 2007.

Bourdieu, P., La Distinction. Critique sociale du jugement, Paris, Minuit, I979.

— Razones prácticas. Sobre la teoría de la acción, trad. T. Kauf, Barcelona, Anagrama, I997.

- Contrafuegos. Reflexiones para servir a la resistencia contra la invasión neoliberal, trad. J. Jordá, Barcelona, Anagrama, I999.

— Lección sobre la lección, trad. T. Kauf, Barcelona, Anagrama, 2002.

CAMPS, V., «Educación y cultura democrática», en S. Giner (coord.), La cultura de la democracia: el futuro, Barcelona, Ariel, 2002, págs. 97-II2.

CASTORIADIS, C., La insignificancia y la imaginación. Diálogos con Daniel Mermet, Octavio Paz, Alain Finkielkraut, Jean-Luc Donnet, Francisco Varela y Alain Connes, trad. J. R. Capella, Madrid, Trotta, 2002.

DerridA, J., La Universidad sin condición, trad. C. de Peretti y P. Vidarte, Madrid, Trotta, 2002.

DuRKheim, E., Educación y Sociología, Buenos Aires, Shapire, I974.

\footnotetext{
${ }^{42}$ DerRida, J., La Universidad sin condición, trad. C. de Peretti y P. Vidarte, Madrid, Trotta, 2002, págs. 9-Io.

${ }^{43}$ Idem, pág. I2. En esta misma línea «deconstructivista» Derrida afirma: «La universidad debería, por lo tanto, ser también el lugar en el que nada está a resguardo de ser cuestionado, ni siquiera la figura actual y determinada de la democracia; ni siquiera tampoco la idea tradicional de crítica, como crítica teórica, ni siquiera la autoridad de la forma 'cuestión', del pensamiento como 'cuestionamiento'» (idem, pág. I4). Cfr. también, SANTOS, De la mano de Alicia: lo social y lo político en la postmodernidad, cit., pág. 274).
} 
ElLACURÍA, I., «Diez años después ¿Es posible una Universidad distinta?», en VV. AA. Universidad y cambio social (Los jesuitas en El Salvador), México D. F., Magna Terra Editores, I990, págs. I3I-66.

Gil Villa, F., El mundo como desilusión. La sociedad nihilista, Madrid, Ediciones Libertarias, I999.

GINER, S., «La Universidad y la falacia utilitarista», documento del encuentro «Los objetivos de la Universidad ante el nuevo siglo», Universidad de Salamanca, noviembre I997 (disponible en www.crue.org).

GINER DE LOS Ríos, F., La Universidad española, Madrid, Civitas, 200I.

Gough, I., Economía política del Estado del bienestar, trad. G. Rodríguez Cabrero, Madrid, H. Blume Ediciones, I982.

MARCovitCH, J., La universidad (im)posible, trad. Y. Machado, Madrid, Cambridge University Press, 2002.

MARTín BARÓ, I., «El estudiantado y la estructura universitaria», en VV. AA., Universidad y cambio social (Los jesuitas en El Salvador), México D. F., Magna Terra Editores, I990, págs. I09-30.

MORIN, E., La mente bien ordenada. Repensar la reforma. Reformar el pensamiento, trad. Mª. J. Buxó y D. Montesinos, Barcelona, Seix Barral, 2000.

- Introducción a una política del hombre, trad. T. Fernández y B. Eguibar, Barcelona, Gedisa, 2002.

PeCes-BARbA, G., «La demanda social a finales del siglo XX», documento del encuentro «Los objetivos de la Universidad ante el nuevo siglo», Universidad de Salamanca, noviembre I997 (disponible en www.crue.org).

SANTOS, B.S., De la mano de Alicia: lo social y lo político en la postmodernidad, trad. C. Bernal, Santafé de Bogotá, Ediciones Uniandes-Facultad de Derecho de la Universidad de los Andes-Siglo del Hombre Editores, I998.

SEgRÉ, M., TANGUY, L. y LORTIE, M. F., «Una nueva ideología de la educación», en Labarca (comp.), Economía política de la educación, México, Editorial Nueva Imagen, i980.

SwIFT, J., Los viajes de Gulliver, trad. P. Hernúñez, Madrid, Anaya, 2oor.

Veblen, Th., Teoría de la clase ociosa, $2^{\mathrm{a}}$ ed. $\mathrm{I}^{\mathrm{a}}$ reimp., trad. V. Herrero, México D. F., Fondo de Cultura Económica, I992. 